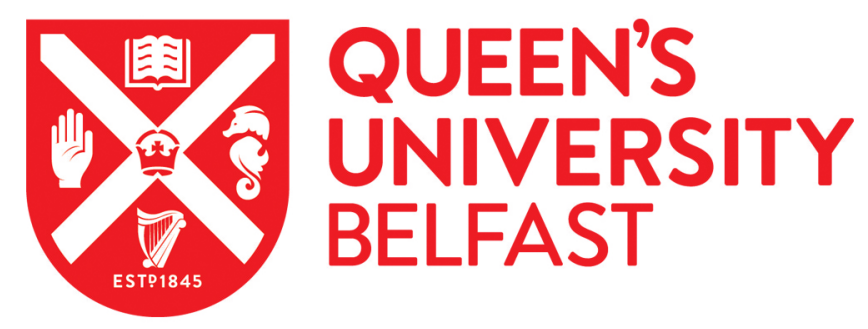

\title{
A comparison of endoscopy versus pathology sizing of colorectal adenomas and potential implications for surveillance colonoscopy
}

Taylor, J. L., Coleman, H., Gray, R. T., Kelly, P. J., Cameron, R. I., O'Neill, C. J., Shah, R. M., Owen, T. A., Dickey, W., \& Loughrey, M. B. (2016). A comparison of endoscopy versus pathology sizing of colorectal adenomas and potential implications for surveillance colonoscopy. Gastrointestinal Endoscopy, 84(2), 341-351. https://doi.org/10.1016/j.gie.2016.04.009

Published in:

Gastrointestinal Endoscopy

Document Version:

Peer reviewed version

Queen's University Belfast - Research Portal:

Link to publication record in Queen's University Belfast Research Portal

Publisher rights

(c) 2016 Elsevier B. V.

This is an open access article published under a Creative Commons Attribution-NonCommercial-NoDerivs License

(https://creativecommons.org/licenses/by-nc-nd/4.0/), which permits distribution and reproduction for non-commercial purposes, provided the author and source are cited.

\section{General rights}

Copyright for the publications made accessible via the Queen's University Belfast Research Portal is retained by the author(s) and / or other copyright owners and it is a condition of accessing these publications that users recognise and abide by the legal requirements associated with these rights.

Take down policy

The Research Portal is Queen's institutional repository that provides access to Queen's research output. Every effort has been made to ensure that content in the Research Portal does not infringe any person's rights, or applicable UK laws. If you discover content in the Research Portal that you believe breaches copyright or violates any law, please contact openaccess@qub.ac.uk. 


\section{Accepted Manuscript}

A comparison of endoscopy versus pathology sizing of colorectal adenomas and potential implications for surveillance colonoscopy

Jennifer L. Taylor, Helen G. Coleman, Ronan T. Gray, Paul J. Kelly, R.I. Cameron, Ciaran J. O'Neill, Rajeev M. Shah, Tracy A. Owen, William Dickey, Maurice B. Loughrey

PII: S0016-5107(16)30055-4

DOI: 10.1016/j.gie.2016.04.009

Reference: YMGE 9968

To appear in: Gastrointestinal Endoscopy

Received Date: 30 September 2015

Accepted Date: 7 April 2016

Please cite this article as: Taylor JL, Coleman HG, Gray RT, Kelly PJ, Cameron RI, O'Neill CJ, Shah RM, Owen TA, Dickey W, Loughrey MB, A comparison of endoscopy versus pathology sizing of colorectal adenomas and potential implications for surveillance colonoscopy, Gastrointestinal Endoscopy (2016), doi: 10.1016/j.gie.2016.04.009.

This is a PDF file of an unedited manuscript that has been accepted for publication. As a service to our customers we are providing this early version of the manuscript. The manuscript will undergo copyediting, typesetting, and review of the resulting proof before it is published in its final form. Please note that during the production process errors may be discovered which could affect the content, and all legal disclaimers that apply to the journal pertain. 


\section{A comparison of endoscopy versus pathology sizing of colorectal adenomas and potential implications for surveillance colonoscopy.}

\section{Short title: Sizing colorectal adenomas}

Authors: Jennifer L Taylor ${ }^{*}$, Helen G Coleman ${ }^{2 *}$, Ronan T Gray², Paul J Kelly1,3, R I Cameron, Ciaran J O'Neill5, Rajeev M. Shah', Tracy A Owen7, William Dickey ${ }^{8}$, and Maurice B Loughrey ${ }^{1,3}$.

*these authors contributed equally to this manuscript

\section{Affiliations:}

1. Department of Histopathology, Royal Victoria Hospital, Belfast Health and Social Care Trust, Belfast, Northern Ireland, BT12 6BA.

2. Centre for Public Health, Queen's University Belfast, Belfast, Northern Ireland, BT12 6BJ.

3. Centre for Cancer Research and Cell Biology, Queen's University Belfast, Belfast, Northern Ireland, BT9 7BL.

4. Department of Pathology, Western Health and Social Care Trust, Altnagelvin Area Hospital, Londonderry, Northern Ireland, BT47 6SB.

5. Department of Cellular and Molecular Pathology, Northern Health and Social Care Trust, Antrim Area Hospital, Antrim, Northern Ireland, BT41 2RL.

6. Department of Pathology, Southern Health and Social Care Trust, Craigavon Area Hospital, Portadown, Northern Ireland, BT63 5QQ.

7. Public Health Agency, Quality Assurance Reference Centre, Northern Ireland Cancer Screening Programmes, Belfast, Northern Ireland, BT2 8HS.

8. Department of Gastroenterology, Western Health and Social Care Trust, Altnagelvin Area Hospital, Londonderry, Northern Ireland, BT47 6SB.

\section{Corresponding author:}

Dr. Maurice B. Loughrey

Department of Histopathology,

Royal Victoria Hospital,

Grosvenor Road,

Belfast BT12 6BA

maurice.loughrey@belfasttrust.hscni.net

Tel. +442890638345 


\section{A comparison of endoscopy versus pathology sizing of colorectal adenomas and potential implications for surveillance colonoscopy}

\section{ABSTRACT}

Background and Aims: To compare endoscopy and pathology sizing in a large population-based series of colorectal adenomas and to evaluate the implications for patient stratification into surveillance colonoscopy.

Methods: Endoscopy and pathology sizes available from intact adenomas removed at colonoscopies performed as part of the Northern Ireland Bowel Cancer Screening Programme, from 2010 to 2015, were included in this study. Chi-squared tests were applied to compare size categories in relation to clinicopathological parameters and colonoscopy surveillance strata according to current American Gastroenterology Association and British Society of Gastroenterology guidelines.

Results: A total of 2521 adenomas from 1467 individuals were included. There was a trend toward larger endoscopy than pathology sizing in 4 of the 5 study centers, but overall sizing concordance was good. Significantly greater clustering with sizing to the nearest $5 \mathrm{~mm}$ was evident in endoscopy versus pathology sizing ( $30 \%$ vs $19 \%, p<0.001$ ), which may result in lower accuracy. Applying a 10-mm cut-off relevant to guidelines on risk stratification, $7.3 \%$ of all adenomas and $28.3 \%$ of those 8 to $12 \mathrm{~mm}$ in size had discordant endoscopy and pathology size categorization. Depending upon which guidelines are applied, $4.8 \%$ to $9.1 \%$ of individuals had differing risk stratification for surveillance recommendations, with the use of pathology sizing resulting in marginally fewer recommended surveillance colonoscopies.

Conclusions: Choice of pathology or endoscopy approaches to determine adenoma size will potentially influence surveillance colonoscopy follow-up in $4.8 \%$ to $9.1 \%$ of individuals. Pathology sizing appears more accurate than endoscopy sizing, and preferential use of pathology size would result in a small, but clinically important, decreased burden on surveillance colonoscopy demand. Careful endoscopy sizing is required for adenomas removed piecemeal. 


\section{INTRODUCTION}

Adenomatous polyps are well-recognized precursors of colorectal cancer (CRC). ${ }^{1}$ The removal of colorectal adenomas has been shown to both reduce the incidence of, and prevent mortality from, CRC. ${ }^{2,3}$ Screening for CRC reduces deaths both by detecting early cancers at a treatable stage, and by detecting and removing adenomatous polyps, the latter being a much more common neoplastic finding at colonoscopy. ${ }^{4}$ Postpolypectomy colonoscopic surveillance is required but it is important to enter patients into an appropriate surveillance regimen that will optimize their reduction in CRC risk and mortality, without overburdening healthcare services.

\section{BACKGROUND}

There is agreement that the need for surveillance colonoscopy and suggested intervals should be determined by the findings at initial colonoscopy. In 2002, and updated in 2010, the British Society of Gastroenterology (BSG) and the Association of Coloproctology for Great Britain and Ireland (ACPGBI) published guidelines for surveillance after colorectal adenoma removal. These suggest stratification of individuals into low, intermediate and high risk based on the number and size of adenomas detected at baseline colonoscopy. ${ }^{5,6} \mathrm{~A}$ cut-off adenoma size of $\geq 10 \mathrm{~mm}$ is specified. In 2006, the United States Multi-Society Task Force on CRC published broadly similar guidelines on post-polypectomy surveillance, updating previous versions. ${ }^{7}$ These guidelines distinguish, for stratification purposes into low or high risk, those individuals with 3 or more adenomas, or any adenoma $\geq 10 \mathrm{~mm}$ in size, with villous features on histology or with high-grade dysplasia (so-called "advanced adenoma") from those with 1 or 2 adenomas $<10 \mathrm{~mm}$ in size. These guidelines have been endorsed and updated by the American Gastroenterology Association (AGA) in $2012 .^{8}$

Surprisingly, none of these guidelines offer any detail on how to measure adenoma size, and specifically whether to use endoscopy or pathology size in recording baseline colonoscopy findings. The reason for this is likely that the cited publications which provide the evidence base for these guidelines variably use endoscopy or pathology size, and most lack any further detail on how size was derived (Table 1). ${ }^{2,9-41}$ Recent guidelines related to CRC screening and management of malignant colorectal polyps have advocated use of pathology size over endoscopy, stating that pathology size is auditable, accurate, simple to perform, and offers the ability to measure the adenomatous component of mixed lesions. ${ }^{42,43}$ There is some evidence to support 
these conclusions but the relevant studies are mostly based on single-center experience and mostly involve small study numbers, ranging from 31 to 235 adenomas. ${ }^{44-50}$ As such, the evidence base for making recommendations on sizing is limited, and requires expansion.

The aim of this large, multicenter study was to compare the endoscopic and pathological sizes recorded for colorectal adenomas removed intact during colonoscopy performed in the setting of a national CRC screening program, in order to identify and quantify factors associated with discordant sizing, to assess the potential impact of discordant adenoma sizing on colonoscopy surveillance and to inform future recommendations for most accurate sizing of adenomas.

\section{METHODS}

\section{Northern Ireland Bowel Cancer Screening Program}

The Northern Ireland Bowel Cancer Screening (BCS) Programme was introduced in April 2010, providing complete coverage of the Northern Ireland population (1.8 million) by 2012. Initially, 2 yearly fecal-occult blood (FOB) detection kits were offered to those individuals aged 60 to 69 years, with subsequent extensions to age 71 years in April 2012 and to age 74 years in April 2014. FOB-positive individuals are offered colonoscopy. BCS colonoscopies are performed in 5 BCS endoscopy centers, each of which has been inspected and approved by the U.K. Joint Advisory Group on endoscopy. Endoscopists performing BCS colonoscopy have undergone formal peer assessment based on personal colonoscopy quality assurance performance and direct observation of procedures.

Four Northern Ireland histopathology laboratories process BCS specimens from the 5 BCS endoscopy centers following an agreed protocol for handling and reporting polypectomy specimens. This protocol includes general instruction on dissecting polypectomy specimens and highlights the importance of accurate sizing of adenomas but, similar to guidance offered in the vast majority of histopathology laboratories, does not offer any more specific instruction on how to do so. Typically, macroscopic assessment in the laboratory provides a 3-dimensional measurement of intact polypectomy specimens and any stalk included is measured separately. Microscopy will indicate the maximum dimension of the adenomatous component of any such specimen, and exclude any non-adenomatous glandular epithelium within surrounding 
flat mucosa or stalk. The World Health Organization definitions of adenoma subtypes are adhered to, tubulovillous adenoma designation requiring $>25 \%$ villous architecture and villous adenoma designation requiring $>75 \%$ villous architecture. ${ }^{51}$

From the inception of the program, detailed histopathology data has been collected centrally on all specimens submitted for histology, including a record of endoscopy and pathology sizes for all adenomas when available.

\section{Case selection}

Within the Northern Ireland BCS Programme, $n=10,008$ histopathological specimens from $n=4256$ colonoscopy episodes have been processed since inception in 2010 up to the end of March 2015. Of the $n=10,008$ BCS specimens, the following diagnoses were excluded from further data analysis for this study: cancers (including "malignant polyps") and specimens diagnosed as suspicious for malignancy ( $n=402)$, normal $(n=489)$, inflammation ( $n=407)$, inflammatory polyp $(n=66)$, benign lymphoid polyp $(n=13)$, hyperplastic polyp ( $n=1530)$, sessile serrated polyp/adenoma/lesion $(n=291)$, traditional serrated adenoma $(n=30)$, or "other diagnosis" $(n=213)$. This left $n=6567$ tubular, tubulovillous, or villous adenomas. Of these, $n=2532$ had both endoscopy and pathology sizes recorded, with piecemeal resection and absent or imprecise (eg, $<10$ $\mathrm{mm}$ ) endoscopy size accounting for the vast majority of excluded adenomas (Fig. 1). A number of approaches were then taken to maximize the accuracy of sizing data recording within the polyp database for adenomas with recorded endoscopy and pathology size. The majority of these sizings were verified as correct. However, $n=10$ were amended to the correct values and $n=11$ were excluded due to being piecemeal resections with pathology sizes inappropriately recorded. After applying these rules, $\mathrm{n}=2521(38 \%)$ adenomas from $\mathrm{n}=1467$ individuals had both endoscopy and pathology sizes recorded and these were retained for inclusion in the statistical analysis. The case selection process is summarized in Figure 1.

\section{Statistical analysis}

Differences in median endoscopy and pathology sizes for adenomas were evaluated by applying the Wilcoxon signed-rank test of medians. A Bland-Altman plot was created to compare agreement by plotting the size difference (endoscopy minus pathology size) against the average of endoscopy and pathology sizes for each adenoma. Size difference was normally distributed. Histograms were generated to compare clustering 
within endoscopy and pathology sizing, and the proportion of adenomas sized at $5 \mathrm{~mm}$ increments (in the 0-50 $\mathrm{mm}$ range) compared using a chi-squared test. The number of adenomas sized at 5-mm intervals is an indicator of probable rounding up or down of sizes, implying a less-accurate approach to measurement. Adenoma sizes were then categorized according to usual strata for surveillance, ie, $<$ or $\geq 10 \mathrm{~mm}$, for purposes of comparison. The association between discordant size classification (endoscopy versus pathology) and other factors was evaluated by chi-squared tests to determine any predictors of discordance, including endoscopy center, pathology laboratory, sex, and adenoma location.

Data were collapsed to evaluate strata based on these size cut-offs for individuals (colonoscopy episodes), also taking into consideration multiplicity, villousness, and highgrade dysplasia to reflect AGA surveillance interval categorization and multiplicity to reflect BSG criteria. Individuals with a concurrent cancer (or suspicious for malignancy) diagnosis in any lesion removed were excluded from this analysis $(n=67)$, leaving $n=1400$ for subsequent analysis. When individuals had multiple adenomas, the priority for classification was (1) agreed large size ( $\geq 10 \mathrm{~mm})$, (2) endoscopy size large but pathology size small (10 mm cut-off), (3) endoscopy size small but pathology size large (10 mm cutoff) and, finally, and (4) agreed small size $(<10 \mathrm{~mm})$.

\section{RESULTS}

Table 2 compares endoscopic and pathological sizing for all $n=2521$ adenomas with available size data, of which $73 \%$ were tubular adenomas and $27 \%$ had a villous component. Adenomas with a villous component were typically larger than tubular adenomas, median sizes $12 \mathrm{~mm}$ and $4 \mathrm{~mm}$, respectively. No significant differences in median values were observed between endoscopy and pathology size for tubular or tubulovillous/villous adenomas. A visual representation of the agreement between endoscopic and pathological sizing for all adenomas is shown in Figure 2. This shows good overall agreement, with a mean size difference of $0.1 \mathrm{~mm}$ ( $95 \%$ limits of agreement, -4.45 to $4.65 \mathrm{~mm}$ ) and with a tendency for endoscopy sizing to be greater than pathology sizing as adenoma size increases.

Figure 3 illustrates the frequencies for the spectrum of recorded adenoma sizes by endoscopy and pathology. Clustering at 5-mm increments was more visible for endoscopy than pathology sizing, evident by clearly more prominent peaks at $5,10,15$, 
and $20 \mathrm{~mm}$. Similarly, when evaluating the proportion of adenomas sized at $5-\mathrm{mm}$ intervals in the entire 0 to $50 \mathrm{~mm}$ range, significantly greater clustering was evident for endoscopy versus pathology sizing ( $30 \%$ versus $19 \%, \mathrm{p}<0.001)$.

The proportions of adenomas classified as small or large according to AGA/BSG criteria $(<10 \mathrm{~mm}$ versus $\geq 10 \mathrm{~mm})$ are shown in Table 3 . Overall, agreement of endoscopy and pathology size classification using this $10 \mathrm{~mm}$ cut-off was very high (92.7\%). Of adenomas with discordant sizes, similar proportions were classified as small based on endoscopy size, but large on pathology size (3.1\%), and vice versa (4.2\%). Discordant stratification was more evident for tubulovillous than tubular adenomas $(p<0.001)$, likely reflecting the larger median size of tubulovillous adenomas. The proportion of adenomas with discordant sizing was much higher when restricting analysis to those in the 8 to $12 \mathrm{~mm}$ size range, with $28.3 \%$ of these $n=528$ adenomas classified differently, applying the $10 \mathrm{~mm}$ cut-off, according to endoscopy or pathology sizing.

When investigating other factors that may predict discordant sizing between endoscopy and pathology, no significant influence of sex or adenoma location was detected (Table 4). However, discordance rate differences between the 5 BCS endoscopy centers were significant (range 4.9-10.5\%, $\mathrm{p}<0.001$ ), with all but one endoscopy center trending toward adenomas being measured larger on endoscopy compared to pathology. Of note, BCS endoscopy centers A and B reflect 2 separate endoscopy services, but both serviced by the same pathology department. Interestingly, discordance within endoscopy center $\mathrm{A}$ had a tendency toward greater endoscopy size than pathology size (7.9\% versus $2.5 \%)$, whereas discordance within endoscopy center $B$ had a tendency toward greater pathology size than endoscopy size (5.2\% versus $2.7 \%)$.

Information was then collapsed to reflect the potential for individuals, rather than adenomas, to be classified differently (with accompanying implications for recommended surveillance) according to endoscopy or pathology sizing, as shown in Table 5. Similar to analysis by individual adenomas, overall sizing concordance was very high $(90.4 \%)$, with only $9.6 \%$ ( $n=135)$ of individuals showing discordance between endoscopy and pathology sizing of their largest adenoma. Regarding implications for surveillance colonoscopy recommendations, the use of pathology size would potentially result in a marginally decreased burden on colonoscopy services compared with using endoscopy size (Table 5). This would lead to $1.1 \%$ more individuals stratified into low risk compared with high-risk categories according to AGA criteria (60.9 vs $62.0 \%$, 
respectively). Similarly, when applying BSG criteria, $2.3 \%$ more individuals would be stratified as low risk if pathology size is applied rather than endoscopy size (49.9\% vs $47.6 \%$, respectively).

Once other factors are taken into consideration, the proportion of patients whose entry into surveillance would be altered due to discordant endoscopy versus pathology sizing is slightly reduced. Using AGA criteria, $n=68$ of the $n=135$ individuals with sizing discordance would be classified as high risk on the basis of high grade dysplasia and/or villousness within their adenomas, and therefore the sizing discordance would not influence stratification. The remaining $n=67(4.8 \%)$ would be stratified on the basis of adenoma sizing and in these individuals the sizing discordance results in differing stratification. Similarly, using BSG criteria, $n=8$ individuals had 5 or more adenomas detected and would be stratified into the high-risk group, regardless of which sizing modality is applied. The remaining $n=127(9.1 \%)$ individuals with sizing discordance and fewer than 5 adenomas, will all have risk stratification determined by whichever sizing modality is applied, and therefore the potential to be placed into an inappropriate surveillance interval.

\section{DISCUSSION}

Accurately measuring colorectal adenomas is of fundamental importance to postpolypectomy surveillance strategies, yet limited guidance is available on whether to use endoscopy or pathology sizes. ${ }^{5-8}$ Table 1 highlights the varied approaches to adenoma sizing within the existing literature that provides the evidence base for both U.S. and U.K. surveillance guidelines. In the largest such study to date, we have compared the endoscopic and pathological sizes recorded for 2521 colorectal adenomas removed intact during colonoscopy performed in the setting of CRC screening, with the aims of identifying and quantifying factors associated with discordant sizing, assessing impact of discordant sizing on colonoscopy surveillance and informing future recommendations for most accurate sizing of adenomas. We found that endoscopy and pathology sizes of adenomas are broadly comparable but that pathology sizing is likely to be more accurate for a variety of reasons and should be used, when available, for clinical decision making. Use of pathology rather than endoscopy sizes would place slightly less burden on surveillance colonoscopy demand. 
The study found good overall concordance between endoscopy and pathology sizing of colorectal adenomas, despite any specific guidance issued to endoscopists or pathologists at the outset, and recognizing a likely wide variety of approaches to sizing, especially within endoscopy practice. A total of $7.3 \%$ of adenomas had discordant endoscopy and pathology sizing with respect to the $10 \mathrm{~mm}$ size cut-off, used in the major international risk stratification systems. ${ }^{5-8}$ Within the 8 to $12 \mathrm{~mm}$ adenoma size range, $28.3 \%$ of adenomas had discordant sizing. This much-higher proportion is unsurprising when restricting analysis to adenomas straddling the cut-off size but does emphasize the need for particular vigilance when assessing adenomas around this size.

There was a slight tendency overall in this study toward larger endoscopy than pathology sizing, with this trend evident in 4 of the 5 endoscopy centers involved. Similarly, most previous related studies, although based on small study numbers and performed in a variety of clinical settings, typically describe larger endoscopy than pathology adenoma sizing. ${ }^{45-47}$ One very recent, large, study which included 1528 polyps (931 adenomas) reported significant endoscopy over-sizing. ${ }^{52}$ Forty-six percent of 222 polyps estimated as $\geq 1 \mathrm{~cm}$ on endoscopy, were $<1 \mathrm{~cm}$ on pathology, in contrast to only $3.9 \%$ of 1306 polyps estimated as $<1 \mathrm{~cm}$ on endoscopy, proving to be $\geq 1 \mathrm{~cm}$ on pathology. Occasional studies have described smaller endoscopy sizing compared with pathology. ${ }^{44,48}$ One study, also performed in the BCS setting within the UK, reported no significant difference between endoscopy size (in vivo) and pathology size (macroscopic, post-fixation). ${ }^{50}$

Endoscopy sizing can be performed in vivo or after retrieval once in the specimen container. ${ }^{48}$ In vivo measurement is visual but can be aided by comparison to an open pair of snare forceps, the diameter of which is $8 \mathrm{~mm}$. This aid is less useful for adenomas much larger than $8 \mathrm{~mm}$. In vivo measurement can be made more difficult if the forceps cannot be opened in the same plane as the maximum diameter of the polyp, or if the polyp is obscured by a mucosal fold. Many potential reasons to explain larger endoscopy than pathology size, relating to both endoscopy and pathology, have been described in previous smaller, single-center studies. ${ }^{44-47,49}$ Visual estimation by the endoscopist, either in vivo or within the specimen container, may encourage rounding up in size, evidenced by clustering at 5-mm increments. Optical instrumentation and camera placement during endoscopy may cause distortion of the polyp image and overestimation of in vivo measurement. There may be shearing of the adenoma during 
withdrawal leading to partial reduction in its size. Formalin fixation has also been reported to cause shrinkage of the polypectomy specimen. Only part of the polyp may be adenomatous microscopically (Fig. 4). Finally, pathology size underestimation may result from inappropriate recording of the largest microscopic adenoma diameter, when the largest adenoma dimension has not been represented on the glass slide.

This study provides some evidence to suggest that endoscopy sizing is less accurate than pathology sizing. First, significantly greater clustering at $5 \mathrm{~mm}$ increments was evident in endoscopy versus pathology sizing, implying less accuracy. This has been reported previously. ${ }^{47,52}$ Several guidelines specifically state that adenoma measurements should be accurate to the nearest millimeter and not rounded to the nearest 5 or $10 \mathrm{~mm} .{ }^{42,43}$ Pathology sizing is perhaps more objective and some endoscopists may have a tendency to round up in size to err on the side of caution with respect to the surveillance colonoscopy interval.

Second, although there was marked variation in endoscopy/pathology sizing discordance between the 5 BCS endoscopy centers (range $4.9 \%-10.5 \%, p<0.001$ ) and this could be due to either endoscopy or pathology factors (or both), 2 endoscopy centers served by the same pathology department demonstrated different trends in discordance, one with endoscopy sizes generally larger than pathology and the other with pathology sizes generally larger than endoscopy. As it seems highly unlikely that the approach to pathology reporting should vary between these 2 centers, this strongly suggests different approaches to endoscopy sizing between these 2 centers.

Many studies have concluded that formalin fixation does not result in significant adenoma shrinkage, and so this explanation for sizing discordance can be largely discounted. ${ }^{44,45,49}$ Clearly, polyps that are only partly adenomatous can only be accurately assessed microscopically, using a Vernier scale or eyepiece graticule. Polypectomy specimens that include a margin of surrounding normal mucosa may be difficult to accurately size at endoscopy or at any stage before microscopy. Several recent guidelines have made the general recommendation that the microscopic pathology size is used because it is considered auditable, simple to perform, and able to assess the adenomatous component of mixed lesions. ${ }^{42,43}$ Larger adenomas may be most easily measured using a magnified graticule/measuring cylinder. ${ }^{47,53}$ 
Microscopy allows measurement only of the 2 dimensions represented on the glass slide. Therefore, if at polyp dissection, the maximum dimension is not presented, by sectioning through the largest polyp axis, microscopic measurement will be an underestimate. It is imperative that, during specimen dissection in the pathology laboratory post-fixation, every effort is made to represent the largest polyp dimension on the glass slide and, furthermore, if this has not been possible, this information is conveyed clearly to the reporting pathologist, whose microscopic adenoma measurement is then largely meaningless, unless only a portion of the lesion is adenomatous. If the whole polyp is adenomatous, it is appropriate to record the fixed macroscopic size as the maximum adenoma dimension.

For most accurate adenoma sizing across a broad range of sizes, we propose that a combined approach is required, using endoscopy size for piecemeal resections, postformalin fixation macroscopic size for adenomas too large to depict in entirety on glass slide and microscopic measurement for small adenomas or polyps with only a partial adenomatous component. Careful communication is required between endoscopist, dissector and reporting pathologist, to arrive at the most accurate size. Greatest attention to endoscopic sizing is required in vivo before a piecemeal resection, at this provides the only opportunity for accurate sizing. If endoscopy and pathology sizes are available on adenomas removed intact, clinical decision making should be based on the pathology size. A suggested algorithm, summarizing this approach to sizing adenomas, is depicted in Figure 5.

Regarding the implications of adenoma sizing on surveillance, our analysis by individual, taking into consideration additional stratification criteria as well as adenoma size, indicated that use of endoscopy rather than pathology size would place a slightly greater burden on colonoscopy resources. More significantly, depending on which sizing modality was used, $4.8 \%$ and $9.1 \%$ of individuals would be placed into different AGA and BSG risk categories, respectively, and potentially offered different colonoscopy surveillance intervals. A similar conclusion was reached in a recent, large study which estimated potentially inappropriate surveillance recommendation in up to $10 \%$ of individuals with adenomas detected at colonoscopy, if endoscopy sizing was applied. ${ }^{52}$ This study however considered only adenoma size in this analysis and did not consider adenoma multiplicity, villousness, and dysplasia grade. 
Another related study involving 15 board-certified gastroenterologists, working in a large U.S. academic medical center, demonstrated marked variation in individual endoscopist's ability to accurately size adenomas, assuming pathology size as the criterion standard, resulting in a significant impact on colonoscopic surveillance recommendations. ${ }^{46}$ Endoscopic mis-sizing resulted in inappropriate risk stratification in $35.2 \%$ (range $0 \%-67 \%$ ) of adenomas, although only adenomas measuring $10 \mathrm{~mm}$ or more endoscopically were included, limiting comparisons with the current study. Of note is the marked variation in endoscopist performance, with some endoscopists seemingly able to accurately reproduce pathology sizing. ${ }^{46}$ With greater uniformity of endoscopy and pathology approaches to adenoma sizing, it is likely that the range of discordance could be considerably narrowed, ideally to the point at which any differences between endoscopy and pathology sizing are of little clinical significance.

It should be noted, however, that the current clinically important 1-cm size cut-off is based on historical endoscopy, and pathology practice and alternation of either methodology should be accompanied by a reappraisal of this threshold for more-intense colonoscopic surveillance, based on data relating to current practice. ${ }^{54}$ More rigorous attention to sizing methodology may generate more-robust data relating to implications of baseline colonoscopy findings for prediction of future risk of colorectal neoplasia. Further stratification of lower risk individuals, who comprised approximately half of all patients in our study, may be possible in future modelling work, perhaps according to adenomas $<5 \mathrm{~mm}$ and those 5 to $10 \mathrm{~mm}$ in size. It is unlikely someone with 2 adenomas measuring 5 to $10 \mathrm{~mm}$ is at the same risk of future neoplasia as someone with a single adenoma $<5 \mathrm{~mm}$ in size, both grouped together under current risk stratification systems. With high-quality colonoscopy, and more accurate sizing assessment of detected polyps, it should be possible to further refine post-polypectomy surveillance, to target resources most appropriately, with the potential for healthcare savings should modeling suggest some relaxation on current surveillance programs is appropriate.

This study has a number of strengths, including its large size and population-based coverage within an organized national BCS program. The specimens included reflect real-world practice and data, in that endoscopists and pathologists involved would not have altered their approaches to adenoma sizing as a result of a study hypothesis. There are some limitations to our study. We were only able to include $38 \%$ of all adenomas removed, due to either pathology or endoscopy size data being unavailable. Piecemeal 
resections and lack of provision of precise endoscopy sizes accounted for a large proportion of these. Nevertheless, this is the largest study to date comparing endoscopy and pathology adenoma sizing measurements. An additional limitation is that the participants of the BCS program reflect a "high-risk" population who have tested positive at FOB testing, and it is possible that our results may not be generalizable to adenomas excised from other age groups or non-screening populations. Similarly, it is also unclear whether conclusions from this study can be extrapolated to the nonscreening setting, in which attention to colonoscopy and pathology quality assurance is less rigorous. Finally, the stratification estimates do not take into consideration factors such as genetic conditions, family history of cancer and personal history of previous adenomas. However it is unlikely that such factors would be impact on pathology and endoscopy sizing methods, limiting the impact of such factors on the discrepancies reported in this paper.

In conclusion, this study of a large population-based series of colorectal adenomas removed during BCS colonoscopy has shown that although there is overall good concordance between endoscopy and pathology adenoma measurement, discordance in sizing is a problem, and resulted in a potential change in surveillance stratification for $4.8 \%$ to $9.1 \%$ of individuals. It provides some evidence to suggest that pathology sizing of intact adenomas is more accurate than endoscopy sizing, and that preferential use of pathology size, where available, would marginally decrease burden on surveillance colonoscopy demand. A combined endoscopy and pathology approach to adenoma sizing is proposed, in an effort to maximize accuracy.

\section{REFERENCES}

1. Muto T, Bussey HJ, Morson BC. The evolution of cancer of the colon and rectum. Cancer 1975;36:2251-70.

2. Winawer SJ, Zauber AG, Ho MN, O'Brien MJ, Gottlieb LS, Sternberg SS, et al. Prevention of colorectal cancer by colonoscopic polypectomy. the national polyp study workgroup. $\mathrm{N}$ Engl J Med 1993;329:1977-81.

3. Zauber AG, Winawer SJ, O'Brien MJ, Lansdorp-Vogelaar I, van Ballegooijen M, Hankey BF, et al. Colonoscopic polypectomy and long-term prevention of colorectal-cancer deaths. N Engl J Med 2012;366:687-96. 
4. Hewitson P, Glasziou P, Irwig L, Towler B, Watson E. Screening for colorectal cancer using the faecal occult blood test, hemoccult. Cochrane Database Syst Rev 2007;(1)(1):CD001216.

5. Atkin WS, Saunders BP, British Society for Gastroenterology, Association of Coloproctology for Great Britain and Ireland. Surveillance guidelines after removal of colorectal adenomatous polyps. Gut 2002;51 (Suppl 5):V6-9.

6. Cairns SR, Scholefield JH, Steele RJ, Dunlop MG, Thomas HJ, Evans GD, et al. Guidelines for colorectal cancer screening and surveillance in moderate and high risk groups (update from 2002). Gut 2010 May;59:666-89.

7. Winawer SJ, Zauber AG, Fletcher RH, Stillman JS, O'Brien MJ, Levin B, et al. Guidelines for colonoscopy surveillance after polypectomy: A consensus update by the US multi-society task force on colorectal cancer and the american cancer society. Gastroenterology 2006;130:1872-85.

8. Lieberman DA, Rex DK, Winawer SJ, Giardiello FM, Johnson DA, Levin TR, et al. Guidelines for colonoscopy surveillance after screening and polypectomy: A consensus update by the US multisociety task force on colorectal cancer. Gastroenterology 2012;143:844-57.

9. Atkin WS, Morson BC, Cuzick J. Long-term risk of colorectal cancer after excision of rectosigmoid adenomas. N Engl J Med 1992;326:658-62.

10. Avidan B, Sonnenberg A, Schnell TG, Leya J, Metz A, Sontag SJ. New occurrence and recurrence of neoplasms within 5 years of a screening colonoscopy. Am J Gastroenterol 2002;97:1524-9.

11. Bertario L, Russo A, Sala P, Pizzetti P, Ballardini G, Andreola S, et al. Predictors of metachronous colorectal neoplasms in sporadic adenoma patients. Int J Cancer 2003;105:82-7.

12. Blumberg D, Opelka FG, Hicks TC, Timmcke AE, Beck DE. Significance of a normal surveillance colonoscopy in patients with a history of adenomatous polyps. Dis Colon Rectum 2000;43:1084,91; discussion 1091-2.

13. Bonithon-Kopp C, Piard F, Fenger C, Cabeza E, O'Morain C, Kronborg O, et al. Colorectal adenoma characteristics as predictors of recurrence. Dis Colon Rectum 2004;47:323-33.

14. Chung SJ, Kim YS, Yang SY, Song JH, Kim D, Park MJ, et al. Five-year risk for advanced colorectal neoplasia after initial colonoscopy according to the baseline risk stratification: a prospective study in 2452 asymptomatic koreans. Gut 2011;60:1537-43. 
15. Cottet V, Jooste V, Fournel I, Bouvier AM, Faivre J, Bonithon-Kopp C. Long-term risk of colorectal cancer after adenoma removal: A population-based cohort study. Gut 2012;61:1180-6.

16. Fossi S, Bazzoli F, Ricciardiello L, Nicolini G, Zagari RM, Pozzato P, et al. Incidence and recurrence rates of colorectal adenomas in first-degree asymptomatic relatives of patients with colon cancer. Am J Gastroenterol 2001;96:1601-4.

17. Jorgensen $O D$, Kronborg $O$, Fenger $C$. A randomized surveillance study of patients with pedunculated and small sessile tubular and tubulovillous adenomas. the funen adenoma follow-up study. Scand J Gastroenterol 1995;30:686-92.

18. Laiyemo AO, Murphy G, Albert PS, Sansbury LB, Wang Z, Cross AJ, et al. Postpolypectomy colonoscopy surveillance guidelines: Predictive accuracy for advanced adenoma at 4 years. Ann Intern Med 2008;148:419-26.

19. Lieberman DA, Weiss DG, Harford WV, Ahnen DJ, Provenzale D, Sontag SJ, et al. Five-year colon surveillance after screening colonoscopy. Gastroenterology 2007;133:1077-85.

20. Martinez ME, Sampliner R, Marshall JR, Bhattacharyya AK, Reid ME, Alberts DS. Adenoma characteristics as risk factors for recurrence of advanced adenomas. Gastroenterology 2001;120:1077-83.

21. Martinez ME, Baron JA, Lieberman DA, Schatzkin A, Lanza E, Winawer SJ, et al. A pooled analysis of advanced colorectal neoplasia diagnoses after colonoscopic polypectomy. Gastroenterology 2009;136:832-41.

22. Martinez ME, Reid ME, Guillen-Rodriguez J, Marshall JR, Sampliner R, Aickin M, et al. Design and baseline characteristics of study participants in the wheat bran fiber trial. Cancer Epidemiol Biomarkers Prev 1998;7:813-6.

23. Schatzkin A, Lanza E, Corle D, Lance P, Iber F, Caan B, et al. Lack of effect of a low-fat, high-fiber diet on the recurrence of colorectal adenomas. polyp prevention trial study group. N Engl J Med 2000;342:1149-55.

24. Baron JA, Cole BF, Sandler RS, Haile RW, Ahnen D, Bresalier R, et al. A randomized trial of aspirin to prevent colorectal adenomas. N Engl J Med 2003;348:891-9. 
25. Winawer SJ, Zauber AG, O'Brien MJ, Ho MN, Gottlieb L, Sternberg SS, et al. Randomized comparison of surveillance intervals after colonoscopic removal of newly diagnosed adenomatous polyps. the national polyp study workgroup. N Engl J Med 1993;328:901-6.

26. Alberts DS, Martinez ME, Roe DJ, Guillen-Rodriguez JM, Marshall JR, van Leeuwen JB, et al. Lack of effect of a high-fiber cereal supplement on the recurrence of colorectal adenomas. phoenix colon cancer prevention physicians' network. N Engl J Med 2000;342:1156-62.

27. Baron JA, Beach M, Mandel JS, van Stolk RU, Haile RW, Sandler RS, et al. Calcium supplements for the prevention of colorectal adenomas. calcium polyp prevention study group. N Engl J Med 1999;340:101-7.

28. Greenberg ER, Baron JA, Tosteson TD, Freeman DH,Jr, Beck GJ, Bond JH, et al. A clinical trial of antioxidant vitamins to prevent colorectal adenoma. polyp prevention study group. N Engl J Med 1994;331:141-7.

29. Alberts DS, Martinez ME, Hess LM, Einspahr JG, Green SB, Bhattacharyya AK, et al. Phase III trial of ursodeoxycholic acid to prevent colorectal adenoma recurrence. J Natl Cancer Inst 2005;97:84653.

30. Lieberman DA, Weiss DG, Bond JH, Ahnen DJ, Garewal H, Chejfec G. Use of colonoscopy to screen asymptomatic adults for colorectal cancer. veterans affairs cooperative study group $380 . \mathrm{N}$ Engl J Med 2000;343:162-8.

31. Miller J, Mehta N, Feldman M, Furth E, Ginsberg GG, Yang YX, et al. Findings on serial surveillance colonoscopy in patients with low-risk polyps on initial colonoscopy. J Clin Gastroenterol 2010;44:e46-50.

32. Miller HL, Mukherjee R, Tian J, Nagar AB. Colonoscopy surveillance after polypectomy may be extended beyond five years. J Clin Gastroenterol 2010;44:e162-6.

33. Noshirwani KC, van Stolk RU, Rybicki LA, Beck GJ. Adenoma size and number are predictive of adenoma recurrence: Implications for surveillance colonoscopy. Gastrointest Endosc 2000;51(4 Pt 1):433-7.

34. Nusko G, Mansmann U, Kirchner T, Hahn EG. Risk related surveillance following colorectal polypectomy. Gut 2002;51:424-8. 
35. O'Brien MJ, Winawer SJ, Zauber AG, Gottlieb LS, Sternberg SS, Diaz B, et al. The national polyp study. patient and polyp characteristics associated with high-grade dysplasia in colorectal adenomas. Gastroenterology 1990;98:371-9.

36. Robertson DJ, Greenberg ER, Beach M, Sandler RS, Ahnen D, Haile RW, et al. Colorectal cancer in patients under close colonoscopic surveillance. Gastroenterology 2005;129:34-41.

37. Saini SD, Kim HM, Schoenfeld P. Incidence of advanced adenomas at surveillance colonoscopy in patients with a personal history of colon adenomas: a meta-analysis and systematic review. Gastrointest Endosc 2006;64:614-26.

38. van Stolk RU, Beck GJ, Baron JA, Haile R, Summers R. Adenoma characteristics at first colonoscopy as predictors of adenoma recurrence and characteristics at follow-up. The polyp prevention study group. Gastroenterology 1998;115:13-8.

39. Stryker SJ, Wolff BG, Culp CE, Libbe SD, Ilstrup DM, MacCarty RL. Natural history of untreated colonic polyps. Gastroenterology 1987;93:1009-13.

40. Yamaji Y, Mitsushima T, Ikuma H, Watabe H, Okamoto M, Kawabe T, et al. Incidence and recurrence rates of colorectal adenomas estimated by annually repeated colonoscopies on asymptomatic Japanese. Gut 200;53:568-72.

41. Yang G, Zheng W, Sun QR, Shu XO, Li WD, Yu H, et al. Pathologic features of initial adenomas as predictors for metachronous adenomas of the rectum. J Natl Cancer Inst 1998;90:1661-5.

42. Quirke $P$, Risio $M$, Lambert $R$, von Karsa $L$, Vieth $M$. Quality assurance in pathology in colorectal cancer screening and diagnosis-European recommendations. Virchows Arch 2011;458:1-19.

43. Williams JG, Pullan RD, Hill J, Horgan PG, Salmo E, Buchanan GN, et al. Management of the malignant colorectal polyp: ACPGBI position statement. Colorectal Dis 2013;15 (Suppl 2):1-38.

44. Moug SJ, Vernall N, Saldanha J, McGregor JR, Balsitis M, Diament RH. Endoscopists' estimation of size should not determine surveillance of colonic polyps. Colorectal Dis 2010;12:646-50.

45. Morales TG, Sampliner RE, Garewal HS, Fennerty MB, Aickin M. The difference in colon polyp size before and after removal. Gastrointest Endosc 1996;43:25-8. 
46. Eichenseer PJ, Dhanekula R, Jakate S, Mobarhan S, Melson JE. Endoscopic mis-sizing of polyps changes colorectal cancer surveillance recommendations. Dis Colon Rectum 2013;56:315-21.

47. Levene $Y$, Hutchinson JM, Tinkler-Hundal E, Quirke P, West NP. The correlation between endoscopic and histopathological measurements in colorectal polyps. Histopathology 2015;66:48590.

48. Gopalswamy N, Shenoy VN, Choudhry U, Markert RJ, Peace N, Bhutani MS, et al. Is in vivo measurement of size of polyps during colonoscopy accurate? Gastrointest Endosc 1997;46:497-502.

49. Schoen RE, Gerber LD, Margulies C. The pathologic measurement of polyp size is preferable to the endoscopic estimate. Gastrointest Endosc 1997;46:492-6.

50. Turner JK, Wright M, Morgan M, Williams GT, Dolwani S. A prospective study of the accuracy and concordance between in-situ and postfixation measurements of colorectal polyp size and their potential impact upon surveillance. Eur J Gastroenterol Hepatol 2013;25:562-7.

51. Hamilton S, Bosman F, Boffetta P, llyas M, Morreau H, Nakamura S, et al. Carcinoma of the colon and rectum. In: Bosman F, Carneiro F, Hruban R, Theise N, editors. WHO Classification of Tumours of the Digestive System. 4th ed. Lyon: IARC Press; 2010. p. 131-82.

52. Anderson BW, Smyrk TC, Anderson KS, Mahoney DW, Devens ME, Sweetser SR, et al. Endoscopic overestimation of colorectal polyp size. Gastrointest Endosc 2016;83:201-8.

53. Houghton JP, McManus DT. Dome magnifiers. Histopathology 2004;45:193.

54. Shaw MJ, Shaukat A. Does polyp size scatter matter? Gastrointest Endosc 2016;83:209-11.

\section{FIGURE LEGENDS}

Figure 1. Summary of study case selection process

Figure 2. Bland-Altman plot showing agreement between endoscopy and pathology size for $n=2521$ colorectal adenomas.

Figure 3. Histogram of endoscopy and pathology adenoma sizes demonstrating greater clustering at $5 \mathrm{~mm}$ and $10 \mathrm{~mm}$ intervals in endoscopy sizing. Adenoma size scale restricted to $20 \mathrm{~mm}$. 
Figure 4. Whole glass slide image depicting a $10 \mathrm{~mm}$ diameter polypectomy specimen (endoscopy size and fixed macroscopic pathology size) which demonstrated a $4 \mathrm{~mm}$ diameter tubular adenoma microscopically, emphasizing the importance of microscopic examination (haematoxylin\&eosin).

Figure 5. Suggested multidisciplinary approach toward most accurate sizing of colorectal adenomas.

Guarantor of the article: Maurice B Loughrey.

Specific author contributions: MBL and HGC designed the study, analyzed and interpreted the data. JLT wrote the manuscript and revised the manuscript after review by all co-authors. PJK, RIC, CJO and RS provided data for the study. All of the authors were involved in writing the manuscript and approved the final version.

Financial support: Helen G Coleman is funded by a Cancer Research UK Population Research Postdoctoral Fellowship.

Potential competing interests: None 
Table 1 Summary of recommendations for adenoma sizing within all studies providing original data cited by United Kingdom ${ }^{5,6}$ and United States ${ }^{7,8}$ guidelines for colonoscopy surveillance after adenoma removal $(2,9-41)$.

\begin{tabular}{|c|c|}
\hline Publication & Recommended method of adenoma sizing \\
\hline Alberts 2005 & Not stated \\
\hline Atkin 1992 & Pathology (maximum diameter of fixed specimen) \\
\hline Avidan 2002 & Endoscopy (open biopsy forceps comparison or measured after excision) \\
\hline Baron 1999 & Endoscopy \\
\hline Baron 2003 & Endoscopy \\
\hline Bertario 2003 & Pathology (maximum diameter of fixed specimen) \\
\hline Blumberg 2000 & Endoscopy \\
\hline Bonithon-Kopp 2004 & Endoscopy \\
\hline Chung 2011 & Endoscopy (open biopsy forceps comparison or measured after excision) \\
\hline Cottet 2012 & Pathology \\
\hline Fossi 2001 & Endoscopy \\
\hline Jorgensen 1995 & Endoscopy (measured after excision) \\
\hline Laiyemo 2008 & Endoscopy \\
\hline Lieberman 2007 & Endoscopy (open biopsy forceps comparison) \\
\hline Martinez 2001 & Endoscopy \\
\hline Miller J 2010 & Endoscopy \\
\hline Miller H 2010 & Endoscopy \\
\hline Noshirwani 2000 & Endoscopy \\
\hline Nusko 2002 & Adenomas $\leq 5 \mathrm{~mm}$ : endoscopy (open biopsy forceps comparison) \\
\hline & Adenomas $>5 \mathrm{~mm}$ : pathology \\
\hline Schatzkin 2000 & Endoscopy \\
\hline Stryker 1987 & Barium enema \\
\hline Van Stolk 1998 & Endoscopy \\
\hline O’Brien 1990 & Endoscopy (open biopsy forceps comparison) \\
\hline Yamaji 2004 & Endoscopy (open biopsy forceps comparison) \\
\hline Yang 1998 & Pathology \\
\hline
\end{tabular}


Table 2 Comparison of endoscopic and pathology sizing for all colorectal adenomas.

\begin{tabular}{|lllll|}
\hline & & $\begin{array}{l}\text { Endoscopy size }(\mathrm{mm}) \\
\text { Median (IQR) }\end{array}$ & $\begin{array}{l}\text { Pathology size }(\mathrm{mm}) \\
\text { Median (IQR) }\end{array}$ & $P$ value \\
\hline All adenomas & $2521(100)$ & $5(3-10)$ & $5(3-10)$ & 0.19 \\
Tubular adenoma & $1835(73)$ & $4(3-6)$ & $4(3-7)$ & 0.33 \\
Tubulovillous adenoma* & $686(27)$ & $12(8-15)$ & $12(9-16)$ & 0.29 \\
\hline
\end{tabular}

IQR: Inter-quartile range. ${ }^{*}$ Includes $\mathrm{n}=7$ villous adenomas.

Table 3 Proportion of colorectal adenomas classified as small or large $(<o r \geq 10 \mathrm{~mm})$ by endoscopic and pathology sizing.

\begin{tabular}{|c|c|c|c|c|}
\hline & $\begin{array}{l}\text { Endoscopy } \\
\text { and } \\
\text { Pathology } \\
\text { size <10mm } \\
\mathrm{n}(\%)\end{array}$ & $\begin{array}{l}\text { Endoscopy } \\
\text { size }<10 \mathrm{~mm} \\
\text { and Pathology } \\
\text { size } \geq 10 \mathrm{~mm} \\
\mathrm{n}(\%)\end{array}$ & $\begin{array}{l}\text { Endoscopy } \\
\text { size } \geq 10 \mathrm{~mm} \\
\text { and Pathology } \\
\text { size }<10 \mathrm{~mm} \\
\mathrm{n}(\%)\end{array}$ & $\begin{array}{l}\text { Endoscopy } \\
\text { and } \\
\text { Pathology } \\
\text { size } \geq 10 \mathrm{~mm} \\
\mathrm{n}(\%)\end{array}$ \\
\hline All adenomas & $1709(67.8)$ & $79(3.1)$ & $106(4.2)$ & $627(24.9)$ \\
\hline Tubular adenoma & $1546(84.3)$ & $48(2.6)$ & $58 \quad(3.2)$ & $183(10.0)$ \\
\hline Tubulovillous adenoma & $163(23.8)$ & $31(4.5)$ & $48 \quad(7.0)$ & $444(64.7)$ \\
\hline Restricting to $8-12 \mathrm{~mm}$ adenomas* & $160(30.3)$ & $69(13.1)$ & $80(15.2)$ & $219(41.5)$ \\
\hline
\end{tabular}

*According to pathology size 


\section{ACCEPTED MANUSCRIPT}

Table 4 Factors associated with discordant classification between endoscopic and pathology sizing

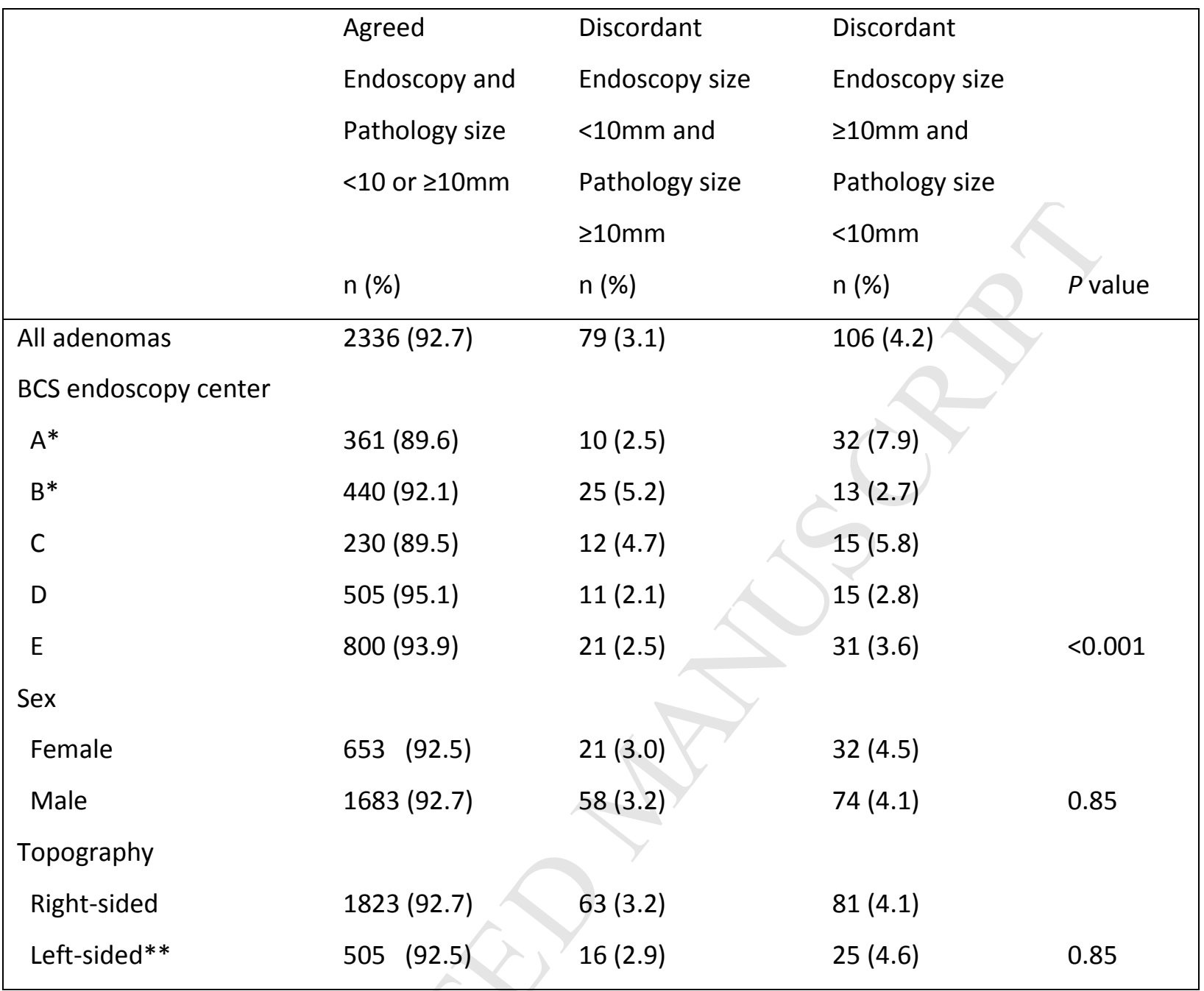

*Same pathology department services these 2 endoscopy centers.

**Left-sided: rectum, rectosigmoid, sigmoid colon, descending colon and splenic flexure. Site was unspecified for $\mathrm{n}=8$ adenomas. 
Table 5 Proportion of individuals stratified into future neoplasia risk and surveillance intervals according to adenoma size and multiplicity.

\begin{tabular}{|c|c|c|c|c|c|}
\hline & Agreed & Discordant & Discordant & Agreed & Total \\
\hline & $\begin{array}{l}\text { Endoscopy and } \\
\text { Pathology size } \\
<10 \mathrm{~mm} \\
\mathrm{n}(\%)\end{array}$ & $\begin{array}{l}\text { Endoscopy size }<10 \mathrm{~mm} \\
\text { and } \\
\text { Pathology size } \geq 10 \mathrm{~mm} \\
\mathrm{n}(\%)\end{array}$ & $\begin{array}{l}\text { Endoscopy size } \geq 10 \mathrm{~mm} \\
\text { and } \\
\text { Pathology size }<10 \mathrm{~mm} \\
\mathrm{n}(\%)\end{array}$ & $\begin{array}{l}\text { Endoscopy and } \\
\text { Pathology size } \\
\geq 10 \mathrm{~mm} \\
\mathrm{n}(\%)\end{array}$ & $\mathrm{n}(\%)$ \\
\hline All adenoma patients & $712(50.9)$ & $52(3.7)$ & $83(5.9)$ & $553(39.5)$ & $1400(100)$ \\
\hline \multicolumn{6}{|l|}{ Multiplicity } \\
\hline $1-2$ & $633(45.2)$ & $33(2.4)$ & $66(4.7)$ & $441(29.4)$ & $1173(83.8)$ \\
\hline $3-4$ & $64(4.6)$ & $16(1.1)$ & $12(0.9)$ & $83 \quad(5.9)$ & $175 \quad(12.5)$ \\
\hline$\geq 5$ & $15(1.1)$ & $3(0.2)$ & $5(0.4)$ & $29 \quad(2.1)$ & $52 \quad(3.7)$ \\
\hline \multicolumn{6}{|c|}{ AGA: multiplicity/HGD/villousness and endoscopy size } \\
\hline Low risk & $514(36.7)$ & $18(1.3)$ & $0(0.0)$ & $0 \quad(0.0)$ & $532(38.0)$ \\
\hline High risk & $198(14.1)$ & $34(2.4)$ & $83(5.9)$ & $553(39.5)$ & $868(62.0)$ \\
\hline \multicolumn{6}{|c|}{ AGA: multiplicity/HGD/villousness and pathology size } \\
\hline Low risk & $514(36.7)$ & $0(0.0)$ & $34(2.4)$ & $0 \quad(0.0)$ & $548(39.1)$ \\
\hline High risk & $198(14.1)$ & $52(3.7)$ & $49(3.5)$ & $553(39.5)$ & $852(60.9)$ \\
\hline \multicolumn{6}{|c|}{ BSG: multiplicity and endoscopy size } \\
\hline Low risk & $633(45.2)$ & $33(2.4)$ & 0 & 0 & $666 \quad(47.6)$ \\
\hline Intermediate risk & $64(4.6)$ & $16(1.1)$ & $66(4.7)$ & $441(29.4)$ & 613 (41.9) \\
\hline High risk & $15(1.1)$ & $3(0.2)$ & $17(1.2)$ & $112(8.0)$ & $111(10.5)$ \\
\hline \multicolumn{6}{|c|}{ BSG: multiplicity and pathology size } \\
\hline Low risk & $633(45.2)$ & 0 & $66(4.7)$ & 0 & 699 (49.9) \\
\hline
\end{tabular}




\begin{tabular}{|c|c|c|c|c|c|}
\hline Intermediate risk & 64 (4.6) & $33(2.4)$ & $12(0.9)$ & $441(29.4)$ & $550 \quad(39.3)$ \\
\hline High risk & 15 (1.1) & $19(1.3)$ & $5(0.4)$ & $112(8.0)$ & 151 \\
\hline
\end{tabular}

All percentages are shown as a $\%$ of $n=1400$ individuals. AGA: American Gastroenterological Association strata into colonoscopy surveillance, determined by adenoma size, multiplicity, villousness and high-grade dysplasia presence.(8) Low risk (1-2 tubular adenomas, each <10 mm, none with high-grade dysplasia): offered 5 to 10 year surveillance; High risk ( $\geq 3$ adenomas, or at least one villous/tubulovillous adenoma, any adenoma with high-grade dysplasia or any adenoma $\geq 10 \mathrm{~mm}$ ): offered 3-year surveillance. BSG: British Society of Gastroenterology strata into colonoscopy surveillance, determined by adenoma size and multiplicity. ${ }^{5}$ Low risk (1-2 adenomas, each <10 mm): offered 5-year or no surveillance; Medium risk (3-4 adenomas, all <10 mm, or any adenoma $\geq 10 \mathrm{~mm}$ ): offered 3-year surveillance; High risk ( 5 or more adenomas of any size, or 3 adenomas with at least $1 \geq 10 \mathrm{~mm}$ ): offered 1 year surveillance. 

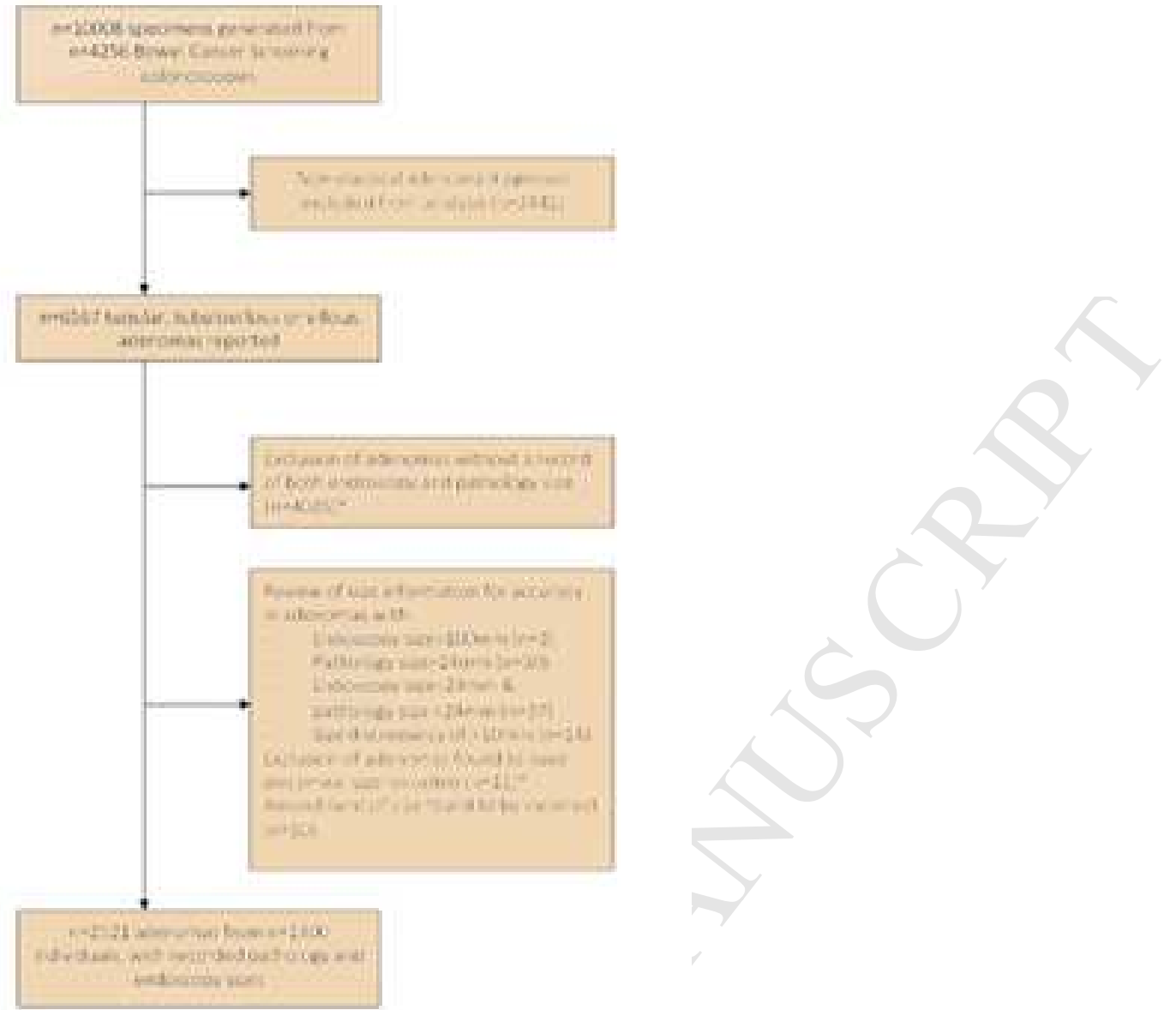

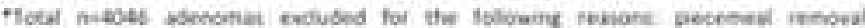

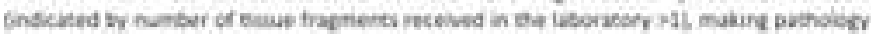

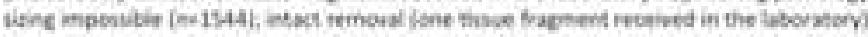

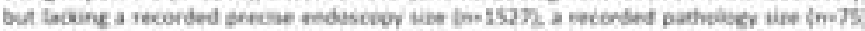

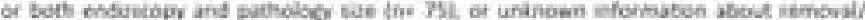

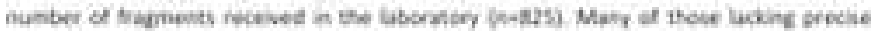

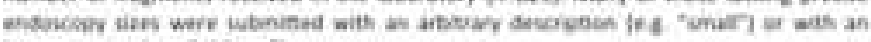
imsrecie we ite "4tomm")

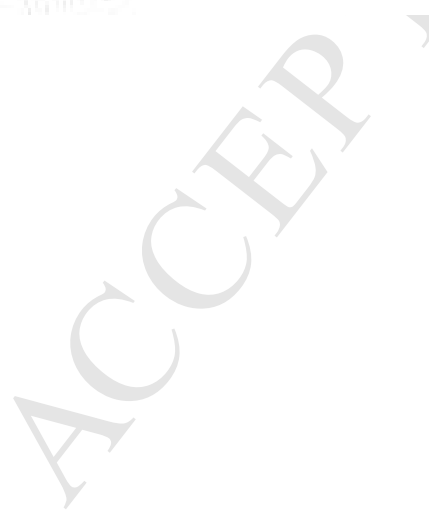




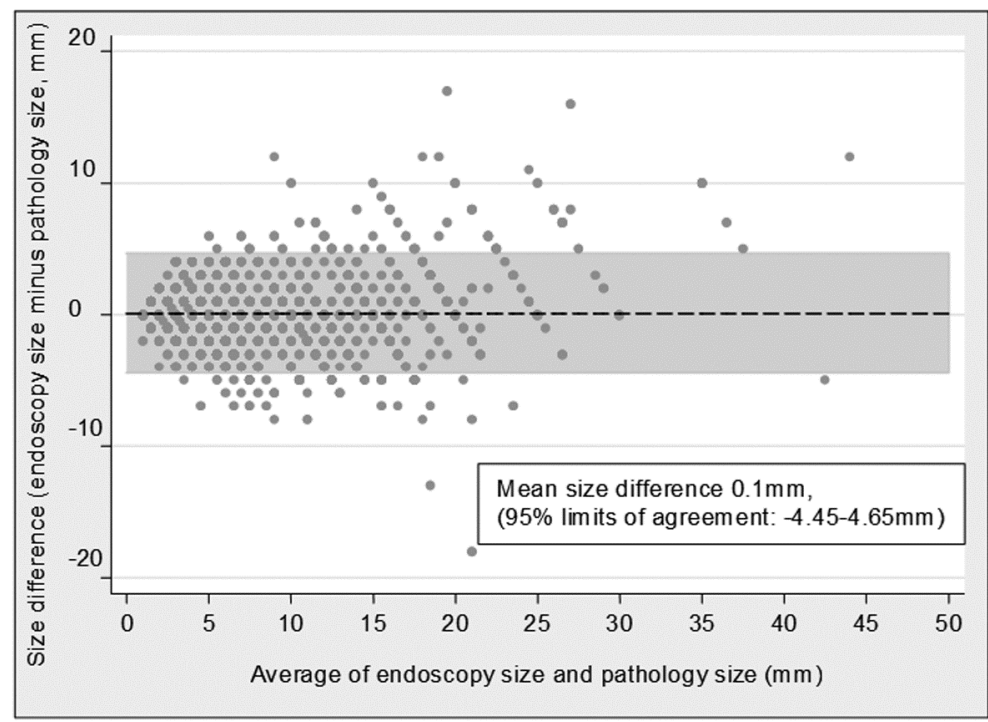




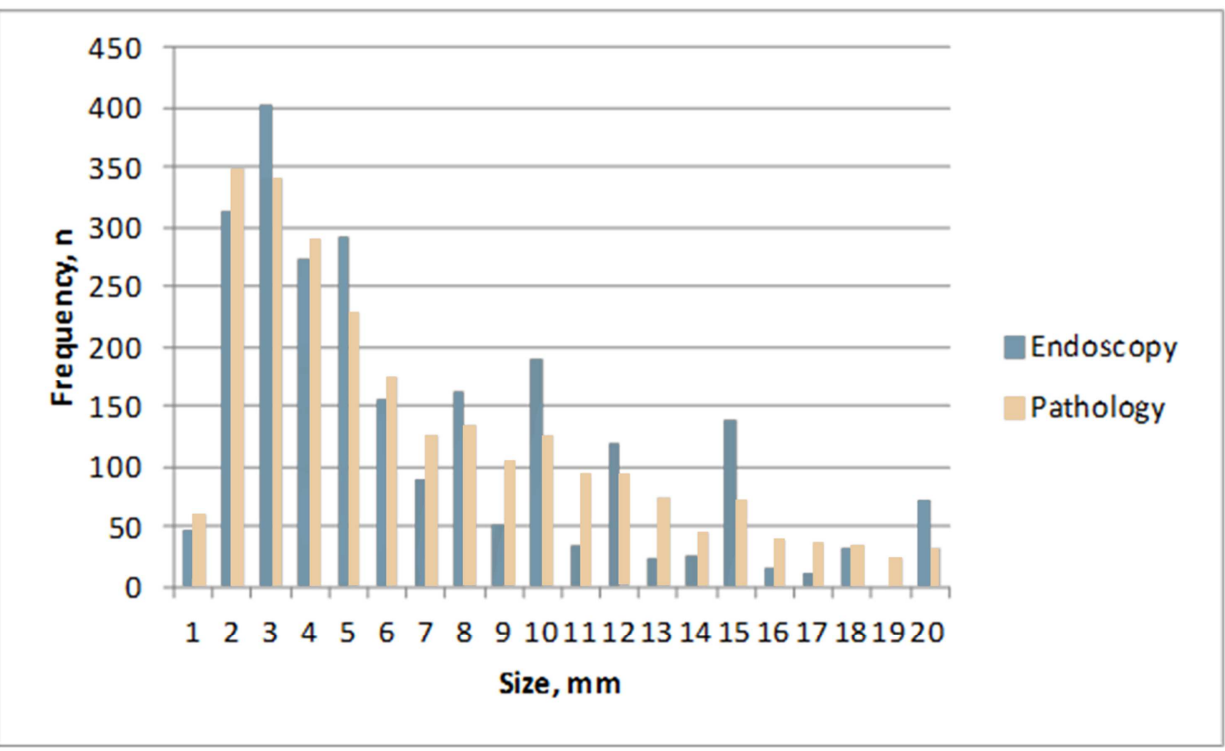




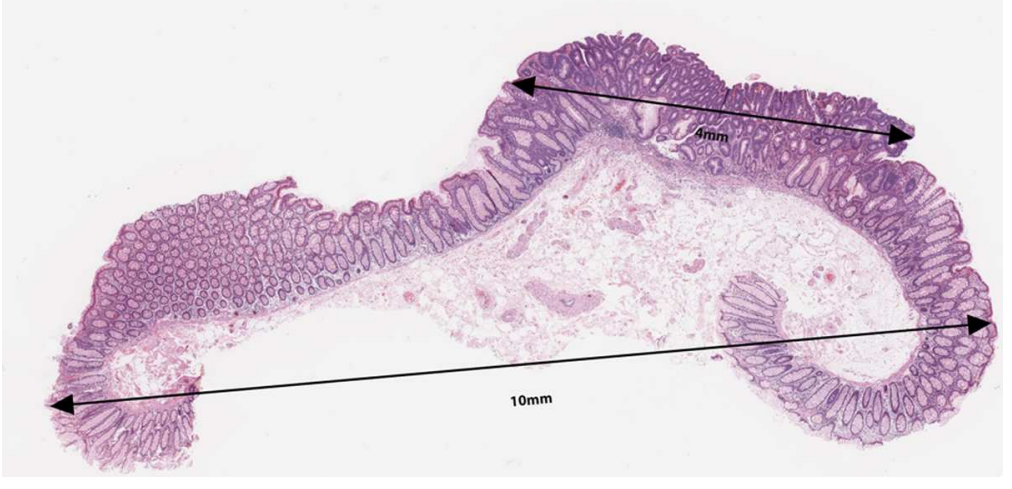




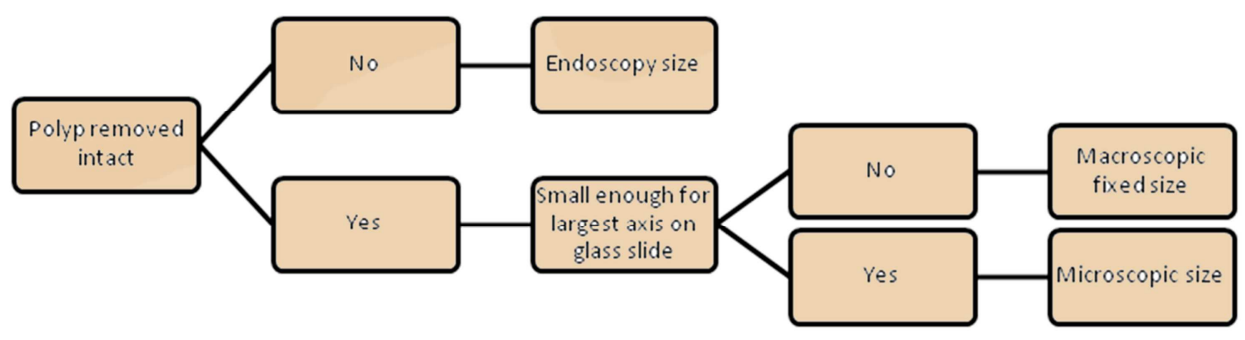


ACPGBI: $\quad$ Association of Coloproctology for Great Britain and Ireland AGA: American Gastroenterology Association

BCS:

Bowel Cancer Screening

BSG: British Society of Gastroenterology

CRC: $\quad$ Colorectal cancer

FOB: $\quad$ Fecal-occult blood 